\title{
Stem cell-based therapies to treat spinal cord injury: a review
}

This article was published in the following Dove Press journal:

Journal of Neurorestoratology

3 July 2017

Number of times this article has been viewed

\author{
Zhongju Shi ${ }^{1,2}$ \\ Hongyun Huang ${ }^{3}$ \\ Shiqing Feng ${ }^{1,2}$ \\ 'Department of Orthopaedics, \\ Tianjin Medical University General \\ Hospital, ${ }^{2}$ Institute of Neurology, \\ Key Laboratory of Post-Neuroinjury \\ Neuro-Repair and Regeneration in \\ Central Nervous System, Ministry \\ of Education, Tianjin City, Tianjin, \\ ${ }^{3}$ Institute of Neurorestoratology, \\ General Hospital of Armed Police \\ Forces, Beijing, People's Republic of \\ China
}

\begin{abstract}
Spinal cord injury (SCI) is a devastating condition and major burden on society and individuals. Currently, neurorestorative strategies, including stem cell therapy products or mature/ functionally differentiated cell-derived cell therapy products, can restore patients with chronic complete SCI to some degree of neurological functions. The stem cells for neurorestoration include neural stem cells, mesenchymal stem cells, embryonic stem cells, induced pluripotent stem cells, etc. A better understanding of the merits, demerits and precise function of different stem cells in the treatment of SCI may aid in the development of neurorestorative strategies. However, the efficacy, safety and ethical concerns of stem cell-based therapy continue to be challenged. Nonetheless, stem cell-based therapies hold promise of widespread applications, particularly in areas of SCI, and have the potential to be novel therapeutics, which contributes to the repair of SCI. This review mainly focused on recent advances regarding the stem cell-based therapies in the treatment of SCI and discussed future perspectives in this field.
\end{abstract}

Keywords: spinal cord injury, neural stem cells, bone marrow-derived mesenchymal stem cells, adipose-derived stem cells, embryonic stem cells, induced pluripotent stem cells

\section{Introduction}

Spinal cord injury (SCI) is a devastating condition resulting from traumatic accidents with a high morbidity and mortality, and there are no effective treatments available by conventional treatments. ${ }^{1-3}$ Currently, neurorestorative strategies, including cell therapy (stem cell products or mature/functionally differentiated cell-derived cell therapy products according to classification of US Food and Drug Administration, ${ }^{85}$ neurostimulation/neuromodulation, neuroprosthesis, neurotization or nerve bridging, neurorehabilitation and combined therapies, can restore patients with chronic complete SCI to some degree of neurological functions. ${ }^{4}$ From the inception of the Orphan Drug Act in 1983 through March 31, 2010, the Office of Orphan Products Development received 27 applications for orphan designation of stem cell-based products (SCBPs); the sources of orphan-designated SCBPs include human embryonic stem cells (hESCs), fetal porcine cells, peripheral blood, umbilical cord blood, mesenchymal tissue, olfactory tissue and bone marrow. ${ }^{5}$ The weight-bearing nature and flexible nature of vertebrae make it particularly susceptible to general SCI. ${ }^{6}$ SCI is characteristically composed of primary injury and secondary injury. ${ }^{7}$ The primary phase is a direct consequence of physical trauma to the spinal cord, and it can cause the discontinuation of axonal projections to release neurotoxic compounds and inflammatory mediators that contribute to neuronal and oligodendroglial cell
Correspondence: Shiqing Feng Department of Orthopaedics, Tianjin Medical University General Hospital, 154 Anshan Road, Heping District, Tianjin 300052, People's Republic of China $\mathrm{Tel} / \mathrm{Fax}+862227183812$

Email sqfeng@tmu.edu.cn 
death. ${ }^{8}$ The secondary pathological injury is a complex damage in the cellular level and occurs over the hours, days and even weeks following the initial injury, including loss of myelin, degeneration of axons and formation of a glial scar that inhibits spontaneous regeneration, and these processes can cause a significant degeneration and consequent functional loss. ${ }^{8,9}$ Furthermore, some factors can contribute to the events after primary SCI, including unbalance of ion, glutamate release and lipid peroxidation. ${ }^{10}$ Until now, a considerable amount of research has been carried out to find a more effective way to restore SCI functions. However, there is still no neuroprotective and regenerative therapies for the injured spinal cord.

Stem cell transplantation was first applied to the patients with cancers of the blood and bone marrow in the 1950s. ${ }^{11}$ Stem cells are defined as cells with the ability to renew themselves continuously and possess pluripotent ability to differentiate into many cell types under particular physiological conditions. ${ }^{12}$ Stem cells are classified into embryonic stem cells (ESCs), fetal stem cells (FSCs) or adult stem cells (ASCs) based on their origin. ${ }^{13}$ Stem cell-based therapies hold promise of widespread applications particularly in SCI areas. ${ }^{14}$ The main advantage of stem cells for treating SCI is their self-renewal capacity. Cell transplantation is considered to be a feasible means to compensate for injury-induced cell and tissue loss following SCI. ${ }^{15}$

The goal of this brief review was to review the recent studies about stem cell-based therapies and advances in the SCI treatment. Further understanding of the potential of stem cell-based therapies may lead to additional therapeutic alternatives in SCI.

\section{Neural stem cells (NSCs)}

NSCs are multipotent populations with the ability to differentiate into neurons, oligodendrocytes and astrocytes. ${ }^{16}$ NSCs are derived from the central nervous system (CNS), including the subventricular zone, the dentate gyrus of the hippocampus and the central canal of the spinal cord. ${ }^{17,18}$ Many studies have explored the possibility of trying to promote functional recovery by transplanting NSCs after SCI. The grafted NSCs can differentiate into appropriate mature neurons. ${ }^{19}$ However, the transplanted NSCs maintain in the state of undifferentiation or are differentiated along the glial lineage after transplantion, ${ }^{20}$ and the past research showed inconsistent results for functional recovery after transplantation. Several studies have overcome the environment unfavorable to neuronal differentiation and achieved good neuronal differentiation of grafted NSCs. ${ }^{21,22}$ Therefore, how to promote the neuronal differentiation tends to be the most concerned thing for transplantation of NSCs.

NSCs-based therapies can not only fill lesion cavities but also provide a supportive substrate for axon regrowth. ${ }^{23}$ Axon regeneration is considered as the one way to restore function after severe SCI. ${ }^{24}$ A previous study confirmed that transplantation of NSCs can cause the long-distance outgrowth of axons from the graft. ${ }^{25}$ However, this study showed that the axons could not regenerate beyond a limited distance within the transplant and enter the host spinal cord. Furthermore, demyelination is one major reason to contribute to functional deficits after SCI. ${ }^{26,27}$ After severe contusive SCI, surviving axons can exhibit demyelination because of the oligodendroglial cell death and limited oligodendrocyte renewal. ${ }^{28,29}$ Oligodendrocyte differentiation of endogenous neural stem cells is inadequate to promote remyelination after SCI. The implanted NSCs are capable of replacing lost oligodendrocytes and remyelinating spared axons and might be helpful to the restoration of function after SCI. ${ }^{30,31}$ Another study have also shown that transplantation of NSCs is effective to replace oligodendrocytes and promote the remyelination of surviving axons after SCI ${ }^{32}$ Therefore, implantation of NSCs has been considered as a potential remyelination strategy for the treatment of SCI.

\section{Mesenchymal stem cells (MSCs)}

MSCs are multipotent prototype or stromal cells having multilineage potential that can differentiate into adipocytes, myocytes, osteocytes and chondrocytes, and the MSCs can be isolated from bone marrow, adipose tissue, placenta, amniotic fluid and umbilical cord. ${ }^{18}$ In the current review, we present our recent understandings on the applications of bone marrow-derived mesenchymal stem cells (BMSCs) and adipose-derived stem cells (ADSCs) in the treatment of SCI.

BMSCs are one of the most studied cell types for SCI. ${ }^{33,34}$ BMSCs can be isolated from bone marrow because of their property of tendency to adhere to tissue culture plastic. ${ }^{35}$ BMSCs have the following advantages: easy to isolate and culture, low immunogenicity, pluripotency and capability to form different phenotypes. ${ }^{36}$ Although previous studies have shown that the transplantation of BMSCs can increase sensory function after SCI, the effects on SCI-induced chronic neuropathic pain are unclear. ${ }^{37-39}$ BMSCs have been reported to overcome germ layer commitment and differentiate into neuron-like cells expressing neuronal markers. ${ }^{40}$ The transplantation of BMSCs can promote the secretion of various immunoregulatory macromolecules that contribute to 
create regenerative microenvironments in the injured spinal cord. ${ }^{41}$ The immunoregulatory phenomenon was considered to be a multifactorial process that requires both direct intercellular contacts and contact-independent paracrine signaling governed through various molecules, including prostaglandin E2 (PGE2), interleukin 6 (IL-6), interleukin 10 (IL-10), inducible nitric oxide synthase (iNOS), indoleamine 2,3-dioxygenase (IDO), tumor necrosis factor-inducible gene 6 protein (TSG-6) and so on. ${ }^{42}$ These molecules participate in the processes of proliferation, differentiation, migration or apoptosis in different immune cells. ${ }^{43}$ Furthermore, a previous study showed that infusion of BMSCs could lead to a more reducing cysteine (Cys) and glutathione (GSH) redox state and had antioxidant effects in vivo. ${ }^{44} \mathrm{~A}$ previous study suggested that treatment with BMSCs had a positive effect on behavioral outcome and histopathological assessment after SCI. ${ }^{45}$ In other studies, the authors injected BMSCs intravenously, and this could facilitate remyelination after SCI and locomotor recovery. ${ }^{46,47}$ Compared with intraspinal injection, intravenous injection has the advantage of minimally invasive and minimal hemorrhage incidence. ${ }^{48} \mathrm{~A}$ recent study showed that using magnets could increase the targeting efficiency and enhance the efficiency of stem cell delivery in SCI. ${ }^{48,49}$ However, the underlying mechanisms of BMSCs' protective effects in SCI are still unclear and need to be further investigated.

ADSCs are isolated from the stromal vascular fraction (SVF) of adipose tissue, and they have a strong resemblance to BMSCs due to their common cell surface markers, similar gene expression profiles and similar differentiation potentials. ${ }^{50-52}$ ADSCs have recently been identified as alternative stem cells, and previous studies have shown that the cells could survive and integrate into the spinal cord. ${ }^{53,54}$ ADSCs have been an ideal choice for cell replacement therapy, and ADSCs have the following advantages: easy to isolate and culture, reliable biosafety and free of immunogenicity. ${ }^{55,56} \mathrm{~A}$ previous study that used rat models of spinal cord contusion injury showed that injection of ADSC-transdifferentiated motor neurons into the impact site and transplantation of glial cell line-derived neurotrophic factor-gelfoam complex into the myelin sheath after 7 days exhibited beneficial effects on recovery of motor function. ${ }^{57}$ Transplanted ADSCs can significantly decrease astrocytic network and stimulate axonal sprouting. ${ }^{58}$ Moreover, transplantation of three-dimensional (3D) cell mass of adipose-derived stem cells (3DCM-ADSCs) significantly improved functional recovery compared with transplantation of ASCs, and this finding may be effective for the treatment of SCI and neural ischemia. ${ }^{59}$ Neurogenin-2
(Ngn2) is a gene that promotes neuronal differentiation, and a previous study showed that transplantation of Ngn2overexpressed ADSCs can improve the local microenvironment and promote the functional recovery after SCI. ${ }^{60}$ Therefore, this study suggested that ADSCs might provide an ideal source for further stem cell research with potential therapeutic application for SCI.

\section{Embryonic stem cells (ESCs) and induced pluripotent stem cells (iPSCs)}

ESCs are pluripotent cells derived from the inner cell mass of a 1-week blastocyst. ${ }^{61}$ The chief difficulty with the use of ESCs is the immunogenicity, and then, ESCs can stimulate the immune response. ${ }^{62}$ Transplantation of ESCs may be a practical approach to treat SCI because they can be repeatedly passaged in culture and differentiated into neuronal or glial cells for transplantation. ${ }^{63}$ ESCs can directly differentiate to oligodendrocytes and secrete trophic factors, such as hepatocyte growth factor and brain-derived neurotropic factor (BDNF), which may be beneficial for promoting axonal regeneration and neurite outgrowth after SCI. ${ }^{64}$ In another study, the implanted ESCs could not only restore lost myelin in the injured spinal cord but also differentiate into mature oligodendrocytes that were capable of myelinating axons. ${ }^{65}$ Thus, at present, transplantation of hESC-derived neural cells, including neuron and oligodendrocytes, is a promising therapy for SCI. ${ }^{6}$

iPSCs are a type of pluripotent stem cells that can be created from adult somatic cells by "reprogramming" via the transduction of pluripotency genes. ${ }^{6}$ iPSCs are envisaged as advanced source for cell replacement therapy in regenerative medicine. ${ }^{67}$ The key advantage of iPSCs for human cell therapy is avoiding immune rejection, ethical constraints and tissue donation. ${ }^{68}$ However, iPSCs have the potential for uncontrolled proliferation and even tumor formation after transplantation in SCI models. ${ }^{69}$ Therefore, a careful screening of oncogenic capacity is essential prior to transplantation. Some previous studies have developed useful and attractive methods to solve the problem of tumorigenicity. Itakura et $\mathrm{al}^{70}$ found that immunoregulation could ablate tumors that are formed after transplantation, and this probably has to do with the infiltration of inflammatory cells, such as lymphocytes and microglia. Another study showed that inhibition of Notch signaling could induce the NPCs to more mature cells with limited proliferation. ${ }^{71}$ Furthermore, a recent study showed that neuroepithelial-like stem cells from human iPSCs (hiPSlt-NES cells) could differentiate into neural lineages in the 
mouse model of SCI and promote functional recovery of hind limb motor function after transplantation. ${ }^{72}$ Romanyuk et al ${ }^{73}$ used a rat model of thoracic contusion in SCI, and the result showed that transplantation of neural precursors derived from human iPSCs (iPSC-NPs) 1 week after SCI promoted tissue sparing and improvement in motor function. The transplantation field of iPSCs is rapidly progressing, and transplantation of iPSCs' products can produce functional recovery by replacing lost cells and/or modulating the microenvironment; yet iPSCs should be transplanted with caution because of the safety of the cell lines and the risk of tumor formation, which can be harmful to patients.

\section{Problems to overcome in the application of stem cells for $\mathbf{S C I}$}

In this review, we focus on the stem cell therapies that have the potential to repair the injured spinal cord, and the comparison between different types of stem cells is summarized in Table 1. Although recently stem cell therapies have made great progress and are widely accepted in the treatment of SCI for promoting morphological recovery and functional recovery via various mechanisms (Figure 1), but they still face great challenges. First, the insufficient sources and ethical constraints concerning stem cells greatly hindered their clinical application. ${ }^{15}$ Although iPSCs are envisaged as an advanced source for cell replacement therapy without these problems, yet studies with animals are urgently required to demonstrate the efficacy and safety of replacement therapy of iPSCs. Moreover, the issue of stem cell tumorigenicity needs to be considered. Second, the transplanted stem cells often maintain in the state of undifferentiation, and the neuronal induction efficiencies are lower than desirable. The inhibitory microenvironment of injured spinal cord is mainly due to local expression of inhibitory factors and glial scar, and the microenvironment can limit the regenerative capacity of endogenous or transplanted cells. ${ }^{74,75}$ Therefore, how to improve the microenvironment after SCI is related to the survival and differentiation of transplanted stem cells.

Furthermore, another problem is that the transplanted stem cells must be able to make right connections with the host neural network. During recent decades, with the development of tissue engineering, engineered biomaterials have been explored for their ability to support axonal regrowth and neuronal differentiation, and more and more biomaterials are applied to stem cell-based replacement

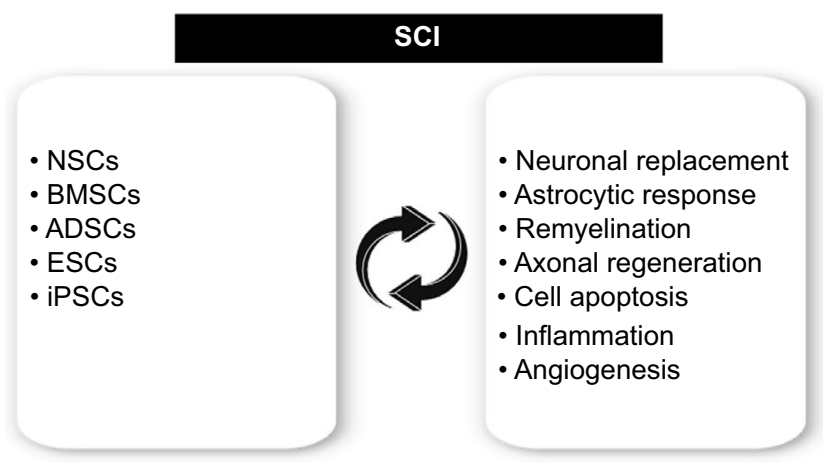

Figure I Major stem cell sources and the therapeutic focus of transplantation of stem cells in $\mathrm{SCl}$.

Abbreviations: $\mathrm{SCl}$, spinal cord injury; $\mathrm{BMSCs}$, bone marrow-derived mesenchymal stem cells; ADSCs, adipose-derived stem cells; ESCs, embryonic stem cells; iPSCs, induced pluripotent stem cells.

Table I Comparison between different types of stem cells

\begin{tabular}{lll}
\hline Types of stem cells & Therapeutic mechanisms and advantages & Disadvantages \\
\hline NSCs & Neuronal replacement therapy & Undifferentiation or differentiation along \\
& Remyelinate the demyelinated axons & the glial lineage after transplantation \\
& Secrete neurotrophic factors & Ethical constraints \\
& Ameliorate T-cell receptor-mediated T-cell activation and inhibit signaling & \\
& of inflammatory cytokines in immune cells & \\
Immunomodulation & Tumorigenicity \\
& Anti-apoptotic effects & \\
& Secrete neurotropic factors and cytokines & \\
& Permissive cellular substrate for promotion of host axonal growth & \\
& Easily extracted and cultivated in large numbers & \\
ESCs & No ethical constraints & Immunogenicity \\
& Can be repeatedly passaged in culture & Ethical constraints \\
iPSCs & Differentiate into neuronal or glial cells & Secrete trophic factors \\
& Avoid immune rejection & Tumorigenicity \\
& No ethical constraints and tissue donation & Genetic and epigenetic abnormalities \\
\hline
\end{tabular}

Abbreviations: NSCs, neural stem cells; MSCs, mesenchymal stem cells; ESCs, embryonic stem cells; iPSCs, induced pluripotent stem cells. 
therapy of SCI. The biocompatible scaffold can provide 3D space; appropriate chemical, physical and mechanical properties for cell proliferation and differentiation and tissue formation and has the potential to transform the inhibitory microenvironment into a permissive transplant microenvironment, which further promotes axonal regrowth. ${ }^{76,77}$ Several types of biomaterials have been suggested for achieving improved functional recovery in the patients with SCI. In a recent study, implanting cetuximab-modified linear-ordered collagen scaffolds (LOCS) into SCI lesion sites in dogs could decrease chondroitin sulfate proteoglycan (CSPG) at the lesion site and results in neuronal regeneration and significant locomotion recovery. ${ }^{78}$ Furthermore, new 3D culture systems have emerged recently that have demonstrated not only the feasibility of creating complex, organized spinal tissue but also how bioengineered 3D scaffolds can be used to control the transplant microenvironment. ${ }^{79} \mathrm{~A}$ previous study demonstrated that a collagen/heparin sulfate scaffold fabricated by a 3D bioprinter could enhance the mechanical properties of collagen and provide continuous guidance channels for axons, which would improve the neurological function in the patients with SCI. ${ }^{80}$ Moreover, nanoparticles can deliver the therapeutic molecules to the target tissue of interest and reduce the side effects of untargeted therapies in unwanted areas; hence, nanobiomedical systems are believed to be potential to provide new therapeutic availability for the treatment of SCI. ${ }^{81}$ Thus, combining neural tissue-engineered scaffolds with stem cell-based therapies can improve transplant efficacy and foster host tissue regeneration, and this combination is the future direction of the stem cell-based therapies following SCI.

Moreover, administration of drug or trophic factors is also a treatment strategy for promoting regeneration of injured spinal cord, and the combination therapy is expected to provide superior clinical effectiveness. ${ }^{82}$ Karimi-Abdolrezaee et $\mathrm{al}^{83}$ added growth factors (epidermal growth factor, basic fibroblast growth factor, platelet-derived growth factor) to chondroitinase $\mathrm{ABC}(\mathrm{C}-\mathrm{ABC})$ and administrated them in the rats after SCI, and this treatment could enhance proliferation of endogenous NPCs, increase new vascular formation and suppress inflammatory reaction. In another study, semaphorin-3A inhibitor was administered to transect spinal cord of rats, and it could promote the elongation of neuronal axons and enhance the Schwann cell-mediated myelination and angiogenesis. ${ }^{84}$

Taken together, although stem cell-based therapies had some problems at present, but they still have good developing prospects, and further investigations will be needed in order to improve the transition to the clinic.

\section{Conclusion}

The main goals of stem cell-based therapies for SCI are the neuron replacement and neurological, structural and functional restoration after SCI. Stem cell-based therapies hold great promise to become an effective therapeutic approach for SCI. Although there are a few different types of stem cells that can serve as a renewable cell source in cell-based therapy for patients suffering from SCI, yet which type of stem cells is most suitable for cell replacement therapy in patients with SCI still needs to be clarified. Furthermore, the efficacy, safety and ethical concerns of stem cell-based replacement therapy continue to be challenged.

\section{Acknowledgment}

This work was supported by the State Key Program of the National Natural Science Foundation of China (81330042); the International Cooperation Program of National Natural Science Foundation of China (81620108018); the Special Program for Sino-Russian Joint Research Sponsored by the Ministry of Science and Technology, China (2014DFR31210) and the Key Program Sponsored by the Tianjin Science and Technology Committee, China (13RCGFSY19000 and 14ZCZDSY00044).

\section{Disclosure}

The authors report no conflicts of interest in this work.

\section{References}

1. Antonic A, Sena ES, Lees JS, et al. Stem cell transplantation in traumatic spinal cord injury: a systematic review and meta-analysis of animal studies. PLoS Biol. 2013;11(12):e1001738.

2. DeVivo MJ, Krause JS, Lammertse DP. Recent trends in mortality and causes of death among persons with spinal cord injury. Arch Phys Med Rehabil. 1999;80(11):1411-1419.

3. Dolbow DR. Exercise following spinal cord injury: physiology to therapy. J Neurorestoratol. 2015;3:133-139.

4. Huang H, Sun T, Chen L, et al. Consensus of clinical neurorestorative progress in patients with complete chronic spinal cord injury. Cell Transplant. 2014;23(suppl 1):S5-S17.

5. Freeman SN, Burke KA, Imoisili MA, Cote TR. The Orphan Drug Act and the development of stem cell-based products for rare diseases. Cell Stem Cell. 2010;7(3):283-287.

6. Doulames VM, Plant GW. Induced pluripotent stem cell therapies for cervical spinal cord injury. Int J Mol Sci. 2016;17(4):530.

7. Kwon BK, Tetzlaff W, Grauer JN, Beiner J, Vaccaro AR. Pathophysiology and pharmacologic treatment of acute spinal cord injury. Spine J. 2004;4(4):451-464.

8. Ben-Hur T. Reconstructing neural circuits using transplanted neural stem cells in the injured spinal cord. J Clin Invest. 2010;120(9):3096-3098.

9. McDonald JW, Becker D. Spinal cord injury: promising interventions and realistic goals. Am J Phys Med Rehabil. 2003;82(10 suppl):S38-S49.

10. Ronaghi M, Erceg S, Moreno-Manzano V, Stojkovic M. Challenges of stem cell therapy for spinal cord injury: human embryonic stem cells, endogenous neural stem cells, or induced pluripotent stem cells? Stem Cells. 2010;28(1):93-99. 
11. Thomas ED, Lochte HL Jr, Lu WC, Ferrebee JW. Intravenous infusion of bone marrow in patients receiving radiation and chemotherapy. N Engl J Med. 1957;257(11):491-496.

12. Kim SU, Lee HJ, Kim YB. Neural stem cell-based treatment for neurodegenerative diseases. Neuropathology. 2013;33(5):491-504.

13. Batista CE, Mariano ED, Marie SK, et al. Stem cells in neurology current perspectives. Arq Neuropsiquiatr. 2014;72(6):457-465.

14. Saberi H, Derakhshanrad N, Yekaninejad MS. Review of recently documented clinical neuroprotective and cellular treatment for spinal cord injury: an analysis of outcomes. J Neurorestoratol. 2014;2:15-24.

15. Sandner B, Prang P, Rivera FJ, Aigner L, Blesch A, Weidner N. Neural stem cells for spinal cord repair. Cell Tissue Res. 2012;349(1): 349-362.

16. Dell'Anno MT, Strittmatter SM. Rewiring the spinal cord: direct and indirect strategies. Neurosci Lett. 2017;652:25-34.

17. Kabatas S, Teng YD. Potential roles of the neural stem cell in the restoration of the injured spinal cord: review of the literature. Turk Neurosurg. 2010;20(2):103-110.

18. Mothe AJ, Tator $\mathrm{CH}$. Advances in stem cell therapy for spinal cord injury. J Clin Invest. 2012;122(11):3824-3834.

19. Pfeifer K, Vroemen M, Caioni M, Aigner L, Bogdahn U, Weidner N. Autologous adult rodent neural progenitor cell transplantation represents a feasible strategy to promote structural repair in the chronically injured spinal cord. Regen Med. 2006;1(2):255-266.

20. Shihabuddin LS, Horner PJ, Ray J, Gage FH. Adult spinal cord stem cells generate neurons after transplantation in the adult dentate gyrus. J Neurosci. 2000;20(23):8727-8735.

21. Han SS, Kang DY, Mujtaba T, Rao MS, Fischer I. Grafted lineagerestricted precursors differentiate exclusively into neurons in the adult spinal cord. Exp Neurol. 2002;177(2):360-375.

22. McDonald JW, Liu XZ, Qu Y, et al. Transplanted embryonic stem cells survive, differentiate and promote recovery in injured rat spinal cord. Nat Med. 1999;5(12):1410-1412.

23. Pfeifer K, Vroemen M, Blesch A, Weidner N. Adult neural progenitor cells provide a permissive guiding substrate for corticospinal axon growth following spinal cord injury. Eur J Neurosci. 2004;20(7): 1695-1704.

24. Tuszynski MH, Steward O. Concepts and methods for the study of axonal regeneration in the CNS. Neuron. 2012;74(5):777-791.

25. Sharp KG, Yee KM, Steward O. A re-assessment of long distance growth and connectivity of neural stem cells after severe spinal cord injury. Exp Neurol. 2014;257:186-204.

26. Basso DM, Beattie MS, Bresnahan JC. Graded histological and locomotor outcomes after spinal cord contusion using the NYU weight-drop device versus transection. Exp Neurol. 1996;139(2):244-256.

27. Gledhill RF, Harrison BM, McDonald WI. Demyelination and remyelination after acute spinal cord compression. Exp Neurol. 1973;38(3):472-487.

28. Crowe MJ, Bresnahan JC, Shuman SL, Masters JN, Beattie MS. Apoptosis and delayed degeneration after spinal cord injury in rats and monkeys. Nat Med. 1997;3(1):73-76.

29. Karimi-Abdolrezaee S, Eftekharpour E, Wang J, Morshead CM, Fehlings MG. Delayed transplantation of adult neural precursor cells promotes remyelination and functional neurological recovery after spinal cord injury. J Neurosci. 2006;26(13):3377-3389.

30. Alizadeh A, Dyck SM, Karimi-Abdolrezaee S. Myelin damage and repair in pathologic CNS: challenges and prospects. Front Mol Neurosci. 2015;8:35.

31. Eftekharpour E, Karimi-Abdolrezaee S, Fehlings MG. Current status of experimental cell replacement approaches to spinal cord injury. Neurosurg Focus. 2008;24(3-4):E19.

32. Cummings BJ, Uchida N, Tamaki SJ, et al. Human neural stem cells differentiate and promote locomotor recovery in spinal cord-injured mice. Proc Natl Acad Sci U S A. 2005;102(39):14069-14074.

33. Chopp M, Zhang XH, Li Y, et al. Spinal cord injury in rat: treatment with bone marrow stromal cell transplantation. Neuroreport. 2000;11(13): 3001-3005.
34. Zurita M, Vaquero J. Bone marrow stromal cells can achieve cure of chronic paraplegic rats: functional and morphological outcome one year after transplantation. Neurosci Lett. 2006;402(1-2):51-56.

35. Wu S, Suzuki Y, Ejiri Y, et al. Bone marrow stromal cells enhance differentiation of cocultured neurosphere cells and promote regeneration of injured spinal cord. J Neurosci Res. 2003;72(3):343-351.

36. Li G, Che MT, Zhang K, et al. Graft of the NT-3 persistent delivery gelatin sponge scaffold promotes axon regeneration, attenuates inflammation, and induces cell migration in rat and canine with spinal cord injury. Biomaterials. 2016;83:233-248.

37. Abrams MB, Dominguez C, Pernold K, et al. Multipotent mesenchymal stromal cells attenuate chronic inflammation and injury-induced sensitivity to mechanical stimuli in experimental spinal cord injury. Restor Neurol Neurosci. 2009;27(4):307-321.

38. Karamouzian S, Nematollahi-Mahani SN, Nakhaee N, Eskandary H. Clinical safety and primary efficacy of bone marrow mesenchymal cell transplantation in subacute spinal cord injured patients. Clin Neurol Neurosurg. 2012;114(7):935-939.

39. Kumagai G, Tsoulfas P, Toh S, McNiece I, Bramlett HM, Dietrich WD. Genetically modified mesenchymal stem cells (MSCs) promote axonal regeneration and prevent hypersensitivity after spinal cord injury. Exp Neurol. 2013;248:369-380.

40. Woodbury D, Schwarz EJ, Prockop DJ, Black IB. Adult rat and human bone marrow stromal cells differentiate into neurons. J Neurosci Res. 2000;61(4):364-370.

41. Zhao H, Cheng L, Du X, et al. Transplantation of cerebral dopamine neurotrophic factor transducted BMSCs in contusion spinal cord injury of rats: promotion of nerve regeneration by alleviating neuroinflammation. Mol Neurobiol. 2016;53(1):187-199.

42. Barrachina L, Remacha AR, Romero A, et al. Effect of inflammatory environment on equine bone marrow derived mesenchymal stem cells immunogenicity and immunomodulatory properties. Vet Immunol Immunopathol. 2016;171:57-65.

43. Ma S, Xie N, Li W, Yuan B, Shi Y, Wang Y. Immunobiology of mesenchymal stem cells. Cell Death Differ. 2014;21(2):216-225.

44. Iyer SS, Torres-Gonzalez E, Neujahr DC, et al. Effect of bone marrow-derived mesenchymal stem cells on endotoxin-induced oxidation of plasma cysteine and glutathione in mice. Stem Cells Int. 2010;2010:868076.

45. Urdzikova L, Jendelova P, Glogarova K, Burian M, Hajek M, Sykova E. Transplantation of bone marrow stem cells as well as mobilization by granulocyte-colony stimulating factor promotes recovery after spinal cord injury in rats. J Neurotrauma. 2006;23(9):1379-1391.

46. Akiyama Y, Radtke C, Honmou O, Kocsis JD. Remyelination of the spinal cord following intravenous delivery of bone marrow cells. Glia. 2002;39(3):229-236.

47. Osaka M, Honmou O, Murakami T, et al. Intravenous administration of mesenchymal stem cells derived from bone marrow after contusive spinal cord injury improves functional outcome. Brain Res. 2010;1343:226-235.

48. Vanecek V, Zablotskii V, Forostyak S, et al. Highly efficient magnetic targeting of mesenchymal stem cells in spinal cord injury. Int J Nanomedicine. 2012;7:3719-3730.

49. Zhang RP, Wang LJ, He S, Xie J, Li JD. Effects of magnetically guided, SPIO-labeled, and neurotrophin-3 gene-modified bone mesenchymal stem cells in a rat model of spinal cord injury. Stem Cells Int. 2016;2016:2018474.

50. Gimble JM, Katz AJ, Bunnell BA. Adipose-derived stem cells for regenerative medicine. Circ Res. 2007;100(9):1249-1260.

51. Lin G, Garcia M, Ning H, et al. Defining stem and progenitor cells within adipose tissue. Stem Cells Dev. 2008;17(6):1053-1063.

52. Schaffler A, Buchler C. Concise review: adipose tissue-derived stromal cells--basic and clinical implications for novel cell-based therapies. Stem Cells. 2007;25(4):818-827.

53. Nogradi A, Pajer K, Marton G. The role of embryonic motoneuron transplants to restore the lost motor function of the injured spinal cord. Ann Anat. 2011;193(4):362-370. 
54. Wei Y, Gong K, Zheng Z, et al. Schwann-like cell differentiation of rat adipose-derived stem cells by indirect co-culture with Schwann cells in vitro. Cell Prolif. 2010;43(6):606-616.

55. Gao S, Zhao P, Lin C, et al. Differentiation of human adipose-derived stem cells into neuron-like cells which are compatible with photocurable threedimensional scaffolds. Tissue Eng Part A. 2014;20(7-8):1271-1284.

56. Zuk PA, Zhu M, Mizuno $\mathrm{H}$, et al. Multilineage cells from human adipose tissue: implications for cell-based therapies. Tissue Eng. 2001;7(2):211-228.

57. Abdanipour A, Tiraihi T, Taheri T. Intraspinal transplantation of motoneuron-like cell combined with delivery of polymer-based glial cell line-derived neurotrophic factor for repair of spinal cord contusion injury. Neural Regen Res. 2014;9(10):1003-1013.

58. Kolar MK, Kingham PJ, Novikova LN, Wiberg M, Novikov LN. The therapeutic effects of human adipose-derived stem cells in a rat cervical spinal cord injury model. Stem Cells Dev. 2014;23(14):1659-1674.

59. Oh JS, Park IS, Kim KN, Yoon DH, Kim SH, Ha Y. Transplantation of an adipose stem cell cluster in a spinal cord injury. Neuroreport. 2012;23(5):277-282.

60. Tang L, Lu X, Zhu R, et al. Adipose-derived stem cells expressing the neurogenin-2 promote functional recovery after spinal cord injury in rat. Cell Mol Neurobiol. 2016;36(5):657-667.

61. Schroeder GD, Kepler CK, Vaccaro AR. The use of cell transplantation in spinal cord injuries. J Am Acad Orthop Surg. 2016;24(4):266-275.

62. Nakagawa M, Koyanagi M, Tanabe K, et al. Generation of induced pluripotent stem cells without Myc from mouse and human fibroblasts. Nat Biotechnol. 2008;26(1):101-106.

63. Erceg S, Ronaghi M, Oria M, et al. Transplanted oligodendrocytes and motoneuron progenitors generated from human embryonic stem cells promote locomotor recovery after spinal cord transection. Stem Cells. 2010;28(9):1541-1549.

64. Plemel JR, Keough MB, Duncan GJ, et al. Remyelination after spinal cord injury: is it a target for repair? Prog Neurobiol. 2014;117:54-72.

65. Liu S, Qu Y, Stewart TJ, et al. Embryonic stem cells differentiate into oligodendrocytes and myelinate in culture and after spinal cord transplantation. Proc Natl Acad Sci U S A. 2000;97(11):6126-6131.

66. Lukovic D, Moreno Manzano V, Stojkovic M, Bhattacharya SS, Erceg S. Concise review: human pluripotent stem cells in the treatment of spinal cord injury. Stem Cells. 2012;30(9):1787-1792.

67. All AH, Gharibani P, Gupta S, et al. Early intervention for spinal cord injury with human induced pluripotent stem cells oligodendrocyte progenitors. PLoS One. 2015;10(1):e0116933.

68. Fu X. The immunogenicity of cells derived from induced pluripotent stem cells. Cell Mol Immunol. 2014;11(1):14-16.

69. Tsuji O, Miura K, Okada Y, et al. Therapeutic potential of appropriately evaluated safe-induced pluripotent stem cells for spinal cord injury. Proc Natl Acad Sci U S A. 2010;107(28):12704-12709.

70. Itakura G, Kobayashi Y, Nishimura S, et al. Controlling immune rejection is a fail-safe system against potential tumorigenicity after human iPSCderived neural stem cell transplantation. PLoS One. 2015;10(2):e0116413.
71. Okubo T, Iwanami A, Kohyama J, et al. Pretreatment with a gammasecretase inhibitor prevents tumor-like overgrowth in human iPSCderived transplants for spinal cord injury. Stem Cell Reports. 2016;7(4): 649-663.

72. Fujimoto Y, Abematsu M, Falk A, et al. Treatment of a mouse model of spinal cord injury by transplantation of human induced pluripotent stem cell-derived long-term self-renewing neuroepithelial-like stem cells. Stem Cells. 2012;30(6):1163-1173.

73. Romanyuk N, Amemori T, Turnovcova K, et al. Beneficial effect of human induced pluripotent stem cell-derived neural precursors in spinal cord injury repair. Cell Transplant. 2015;24(9):1781-1797.

74. Enomoto M. Therapeutic effects of neurotrophic factors in experimental spinal cord injury models. J Neurorestoratol. 2016;4:15-22.

75. Fuhrmann T, Anandakumaran PN, Shoichet MS. Combinatorial therapies after spinal cord injury: how can biomaterials help? Adv Healthc Mater. Epub 2017 Mar 1.

76. Raspa A, Pugliese R, Maleki M, Gelain F. Recent therapeutic approaches for spinal cord injury. Biotechnol Bioeng. 2016;113(2):253-259.

77. Slotkin JR, Pritchard CD, Luque B, et al. Biodegradable scaffolds promote tissue remodeling and functional improvement in non-human primates with acute spinal cord injury. Biomaterials. 2017;123: 63-76

78. Li X, Zhao Y, Cheng S, et al. Cetuximab modified collagen scaffold directs neurogenesis of injury-activated endogenous neural stem cells for acute spinal cord injury repair. Biomaterials. 2017;137:73-86.

79. Iyer NR, Wilems TS, Sakiyama-Elbert SE. Stem cells for spinal cord injury: strategies to inform differentiation and transplantation. Biotechnol Bioeng. 2017;114(2):245-259.

80. Chen C, Zhao ML, Zhang RK, et al. Collagen/heparin sulfate scaffolds fabricated by a 3D bioprinter improved mechanical properties and neurological function after spinal cord injury in rats. J Biomed Mater Res A. 2017;105(5):1324-1332.

81. Nejati-Koshki K, Mortazavi Y, Pilehvar-Soltanahmadi Y, Sheoran $\mathrm{S}$, Zarghami N. An update on application of nanotechnology and stem cells in spinal cord injury regeneration. Biomed Pharmacother. 2017;90:85-92.

82. Nagoshi N, Okano H. Applications of induced pluripotent stem cell technologies in spinal cord injury. J Neurochem. Epub 2017 Feb 15.

83. Karimi-Abdolrezaee S, Schut D, Wang J, Fehlings MG. Chondroitinase and growth factors enhance activation and oligodendrocyte differentiation of endogenous neural precursor cells after spinal cord injury. PLoS One. 2012;7(5):e37589.

84. Kaneko S, Iwanami A, Nakamura M, et al. A selective Sema3A inhibitor enhances regenerative responses and functional recovery of the injured spinal cord. Nat Med. 2006;12(12):1380-1389.

85. US Food \& Drug Administration. Vaccines, Blood \& Biologics. Available from: https:/www.fda.gov/BiologicsBloodVaccines/GuidanceComplianceRegulatoryInformation/Guidances/default.htm. Accessed April 18, 2017.
Journal of Neurorestoratology

\section{Publish your work in this journal}

The Journal of Neurorestoratology is an international, peer-reviewed open access online journal publishing original research and review articles on the subject of Neurorestoratology. To provide complete coverage of this revolutionary field the Journal of Neurorestoratology will report on relevant experimental research, technological advances, and clinical achievements. The manuscript management system is completely online and includes a very quick and fair peer-review system, which is all easy to use. Visit http://www.dovepress.com/testimonials. php to read real quotes from published authors. 